\title{
HAMBÚRGUER: EVOLUÇÃO COMERCIAL E PADRÕES MICROBIOLÓGICOS
}

\author{
MARIA DA GRAÇA FICHEL DO NASCIMENTO* \\ CARLOS ZARDEN FEITOSA DE OLIVEIRA** \\ ELMIRO ROSENDO DO NASCIMENTO***
}

\begin{abstract}
Neste trabalho de revisão de literatura foram relatados os aspectos evolutivos do hambúrguer (desde sua origem), destacando-se o consumo "per capita" de carne, seu crescimento comercial e consumo contínuos. Foram também abordados os fatores que influenciam a microbiota do hambúrguer e os padrões microbiológicos estabelecidos para o produto pela Agência Nacional de Vigilância Sanitária (ANVISA). Adicionalmente, discutiu-se o emprego da Contagem Total de Bactérias Mesófilas (CTP) como ferramenta de detecção da qualidade microbiológica em carnes e hambúrgueres e sua exclusão da legislação brasileira. Sugere-se a inclusão de CTP nos padrões adotados para hambúrgueres crus, visando diminuir a carga microbiológica do produto.
\end{abstract}

PALAVRAS-CHAVE: HAMBÚRGUER; CARNE - QUALIDADE MICROBIOLÓGICA; CTP.

\section{INTRODUÇÃO}

Os aspectos relacionados com a excelente qualidade nutricional da carne bovina são bem conhecidos. Porém, conforme discutido por PRADO et al. (2004), o problema com a carne bovina envolve seu elevado teor de ácidos graxos saturados e baixo teor de insaturados. Algumas perspectivas para redução dos ácidos graxos saturados na carne são mencionadas e propostas para o futuro, utilizando cruzamento de raças e suplementações alimentares (PRADO et al. 2004). Mesmo assim,

\footnotetext{
* Pesquisador, Ph.D. em Microbiologia e Segurança Alimentar, Embrapa Agroindústria de Alimentos, Rio de Janeiro, RJ. (e-mail: graca@ctaa.embrapa.br).

** Professor, MSc. em Medicina Veterinária Preventiva, Fundação Educacional D. André Arcoverde, Centro de Ensino Superior de Valença, Valença, RJ. (e-mail:czarden@uol.com.br).

*** Professor, Ph.D. em Post Doctor, Microbiologia e Epidemiologia Molecular, Universidade Federal Fluminense, Niterói, RJ. (e-mail: mironascimento@hotmail.com).
} 
diante do cenário mundial, a bovinocultura brasileira tem crescido e experimentado aumento não só no consumo interno mas também nas exportações de carne.

O objetivo deste trabalho foi apresentar a evolução comercial e o crescimento contínuo do consumo de hambúrguer e da carne bovina, abordando os parâmetros intrínsicos e extrínsicos que afetam sua qualidade microbiológica. Além disso, discutiu-se o emprego da Contagem Total de Bactérias Mesófilas (CTP), enfatizando sua importância como ferramenta no diagnóstico de qualidade microbiológica de carnes e hambúrgueres.

\section{CONSUMO DE CARNES}

O consumo da carne bovina apresentou queda mais acentuada entre 1996 e 1998. Observa-se na Figura 1, a evolução do consumo "per capita" das carnes de bovinos, frangos e suínos no Brasil, a partir de 1990. O principal motivo da referida queda foi a propaganda contra o consumo de alimentos com colesterol. Paralelamente, observa-se em todo o período crescimento praticamente contínuo do consumo da carne de frangos e menos acelerado da carne de suínos. Em 2002, o consumo "per capita" brasileiro para esses três tipos de carnes evidenciou leve acréscimo, representando respectivamente, 35,8\%, 33,2\% e 12,3\%, para bovinos, frangos e suínos (PERDIGÃO, 2004).

\section{FIGURA 1 - EVOLUÇÃO DO CONSUMO “PER CAPITA” DE CARNES - BRASIL (1990-2004)}

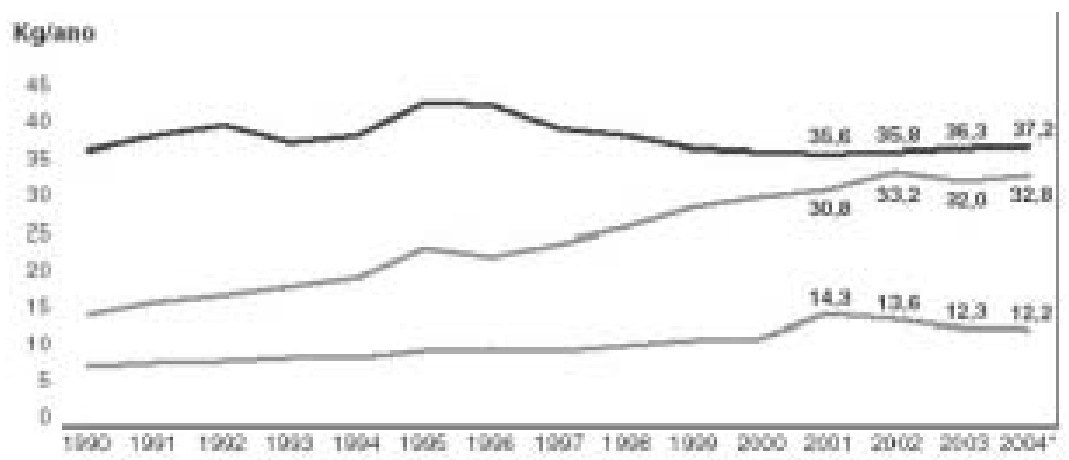

*Projeções.

Fonte: PERDIGÃO (2004). 
Em 2001, ano marcado pelas crises sanitárias, o consumo mundial de carnes aumentou $1,5 \%$, mas o consumo de carne bovina revelou queda de $1,2 \%$ (PINEDA e ALMEIDA, 2003).

A reativação do consumo da carne bovina está relacionada, principalmente, ao aumento do consumo de hambúrgueres não apenas no Brasil, mas em todo o mundo. As gerações mais jovens são menos sensíveis aos argumentos de risco de desenvolvimento de doenças cardíacas pela ingestão de colesterol, e consomem cada vez mais hambúrgueres e refrigerantes. Estudos têm confirmado a tendência de que mantenham esses hábitos pelo resto da vida (GERDAU, 2001).

Segundo FERRAZ, apud MAGOSSI (2000), estimou-se que as exportações de carne bovina brasileira em 2003 atingissem o patamar de 1.150 milhões de toneladas e receita de US\$1,4 bilhões. Isto representaria crescimento de $40,0 \%$ (em volume) no valor estimado para as exportações de carne bovina in natura em 2002 e aumento de 15,0\% para a carne industrializada. Tais projeções estavam baseadas em cenário de crescimento da produção mundial de carne bovina de apenas 1,7\%, gerando a expectativa de aumento das importações de carne nos países cuja produção é insuficiente para atender a demanda. Entretanto, de acordo com dados oficiais (ABIEC, 2004), o volume das exportações de carne bovina atingiu, em 2003, o total de 819 mil t de carne "in natura" e 235 mil t de carne industrializada. Assim o total de 1.054 millões t de carne bovina ficou abaixo da projeção esperada. A maior fatia de crescimento de consumo da carne bovina mundial está prevista para acontecer no setor de carne moída e de hambúrgueres. Tal fato beneficia o Brasil, cujo rebanho pode atender o aumento das importações e ainda conta com a carne de "zebu", considerada ideal para a produção de hambúrgueres.

Na Tabela 1 são apresentados os países europeus que mais consumiram carne bovina, suína e de frango no ano de 2003.

Em comparação com os países europeus (Tabela 1), o Brasil foi o maior consumidor de carne bovina (36,3 kg/hab/ano) considerando-se os dados relativos a 2003 (Figura 1). No "ranking" mundial, o Brasil foi o terceiro maior consumidor de carne bovina em 2003 (USDA, apud RODRIGUES JÚNIOR, 2003), só perdendo para os Estados Unidos da América (41,90 kg/hab/ano) e Austrália (37,50 kg/hab/ano). 


\section{TABELA 1 - UNIÃO EUROPÉIA: CONSUMO "PER CAPITA" DE CARNES (Kg/hab/ano) 2003*}

\begin{tabular}{cccc}
\hline & Aves $^{-}$ & Sunos & Bovinas \\
\hline Espanha & 26,6 & 69,6 & 16,7 \\
\hline Portugal & 28,9 & 44,2 & 16,4 \\
\hline Austria & 17,1 & 56,2 & 18,7 \\
\hline Finiandia & 15,4 & 33,0 & 18,2 \\
\hline Grbcia & 22,7 & 28,6 & 18,2 \\
\hline França & 23,3 & 36,7 & 27,0 \\
\hline Alemanha & 18,9 & 54,7 & 12,4 \\
\hline Italia & 17,2 & 39,0 & 24,8 \\
\hline Subcia & 13,9 & 35,6 & 24,0 \\
\hline Reino Unido & 27,8 & 25,3 & 21,6 \\
\hline Holanda & 21,2 & 42,8 & 19,0 \\
\hline Belgica/Luxemburgo & 16,0 & 44,7 & 17,9 \\
\hline Irlanda & 32,7 & 38,2 & 25,0 \\
\hline Dinamarea & 20,6 & 58,4 &
\end{tabular}

*Dados preliminares.

Fonte: ABIPECS (2004).

O rebanho bovino brasileiro apresentou o maior crescimento em quantidade de animais, em 2002, atingindo o total de 185.347.198 cabeças. Em relação ao tipo de rebanho só perdeu em "galos, frangos, frangas e pintos", com o total de 727.725.761 unidades (IBGE, 2004). Segundo PARIZOTTO (2004), o consumo de carne bovina "per capita" no Brasil era de $23 \mathrm{~kg} / \mathrm{ano}$, em 1994, passando para mais de $36 \mathrm{~kg} / \mathrm{hab} / \mathrm{ano}$ em 2004.

Verificou-se acréscimo na exportação brasileira de carne bovina, congelada e fresca, em termos de milhões de dólares (FOB) de 48,70\% de janeiro/dezembro de 2002 para 2003 e de $44,70 \%$ de janeiro/2003 para janeiro/2004 (AEB, 2004). Segundo SOARES (2004), as exportações brasileiras de carne bovina tiveram aumento de $54 \%$ no primeiro quadrimestre do ano e proporcionaram receita de US $\$ 666.931$ milhões. A previsão de exportação de carne "in natura" para o ano 2004, segundo MOREIRA et al. (2003) é de 1,4 milhões de toneladas.

As exportações brasileiras de carnes bovinas (desossadas, frescas ou refrigeradas), somente para o Chile representaram em 2000, 2001 e 2002, respectivamente, US\$35,6, US\$72,3 e US\$ 88,3 milhões de dólares. A carne bovina foi o principal produto de exportação do Brasil para esse 
País, seguido por óleos brutos de petróleo (INFORMATIVO SECEX, 2003). Ainda foi exportada para o Chile carne bovina sob a forma desossada e congelada, representando (em US\$ milhões FOB) US\$18,1, US\$22,6 e US\$ 23,9, respectivamente, nos anos de 2000, 2001 e 2002 (INFORMATIVO SECEX, 2003).

A modernidade mudou os hábitos do consumidor. Os gastos com compras de produtos industrializados, no Brasil, passaram do patamar de $26,0 \%$ em 1992 para 52,2\% entre os anos de 1994 a 1995 (CAVALCANTI, 1993; METZGER e TEIXEIRA, 1997).

O avanço no mercado de produtos congelados explica a maior procura pelo hambúrguer. Observa-se na Figura 2, parcela significativa do consumo de hambúrgueres em relação aos outros produtos cárneos congelados no Brasil. O consumidor potencial de hambúrgueres mora nas cidades e $81,23 \%$ da população brasileira reside em áreas urbanas (IBGE, 2004). Nos anos de 2000 e 2001, o consumo anual de carnes apresentou aumento médio de 21,3\% (ABAMEC, 2002).

\section{FIGURA 2 - CONSUMO DE CARNES CONGELADAS EM VOLUME (\%) BRASIL/2003}

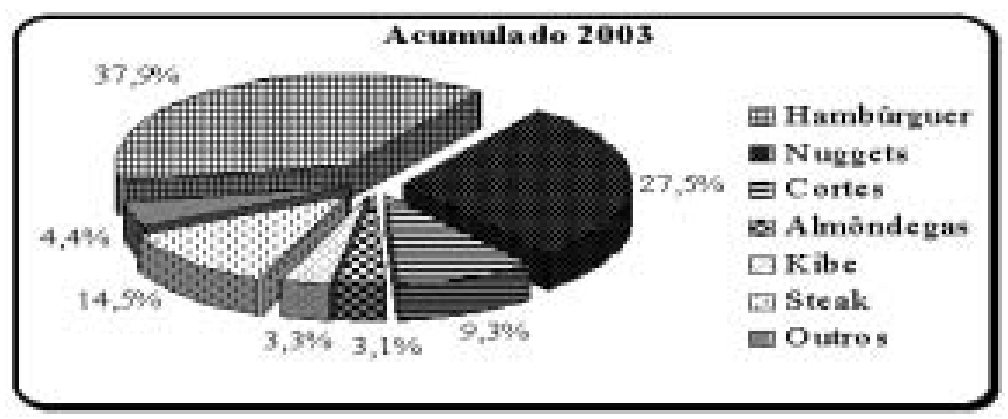

Fonte: NIELSEN apud PERDIGÃO (2004).

A carne bovina e, pararelamente, o hambúrguer tiveram crescimento de produção e consumo fantásticos nas últimas décadas. Em 1960, nos Estados Unidos da América, a produção de carne reestruturada, processada sob Inspeção Federal era de 375.000 toneladas, sendo somente $30 \%$ do total destinado para hambúrgueres. Cerca de 20 anos depois, a produção total de carne aumentou em cerca de $1.000 \%$, passando para 1,3 milhões de toneladas (SINK, 1980). 
Segundo GARNIER, KLONT e PLASTON (2003), o aumento no uso da biotecnologia deverá causar grande impacto econômico na cadeia produtiva de carnes, aumentando a possibilidade de obtenção de produtos diferenciados e melhorando a homogeneidade dos animais vivos. Ressaltaram ainda o crescimento da percepção do consumidor, a qual vem influenciando a cadeia produtiva de alimentos.

As empresas têm como foco o cliente e dependendo da predominância do público/região, esse (foco) será infantil ou adulto. Para se ter idéia da expansão das redes de "fast food" no mercado, basta citar uma das empresas de uma grande rede de restaurantes (cujo principal "fast food" é o hambúrguer) que soma cerca de 598 restaurantes em 128 cidades no Brasil (ION, 2003).

\section{DEFINIÇÃO DE HAMBÚRGUER}

O hambúrguer teve origem na Alemanha, na cidade de Hamburgo, sendo degustado cru. Apareceu nas mesas de um restaurante em Washington em 1889, invadiu os Estados Unidos (a partir da década de 20) de tal forma que não se pensa no estilo de vida norte-americano sem ele. Chegou ao Brasil nos anos 50 e ficou conhecido depois que a primeira rede de "fast food" começou a produzí-lo em larga escala (ALVES, 1999).

Pelo Regulamento Técnico de Identidade e Qualidade de Hambúrguer (BRASIL, 2000) "entende-se por hambúrguer o produto cárneo industrializado, obtido de carne moída dos animais de açougue, adicionado ou não de tecido adiposo e ingredientes, moldado e submetido a processo tecnológico adequado". "Trata-se de produto cru, semi-frito, cozido, frito, congelado ou resfriado" de acordo com sua classificação (BRASIL, 2000).

O Código de Regulamentação Federal dos Estados Unidos (ROMANS et al., 1985) define hambúrguer como: "bife de carne moída, fresco ou congelado, com ou sem adição de gordura e/ou condimentos, que não deve apresentar mais de $30 \%$ de gordura e não deve conter adição de água". Já o regulamento brasileiro permite a adição de água como ingrediente opcional na composição de hambúrguer (BRASIL, 2000).

O produto deve ter como ingrediente obrigatório, carne de diferentes espécies de animais de açougue (BRASIL, 2000). Segundo HOOGENKAMP (1996), os mais populares são os hambúrgueres de carne bovina, com consumo estimado em cerca de $50 \%$ do consumo total mundial de carne bovina. Os ingredientes opcionais incluem gorduras 
animal, vegetal, água, sal, proteínas (animal e/ou vegetal), leite em pó, açúcares, maltodextrina, aditivos intencionais, condimentos, aromas e especiarias, além de vegetais, queijos e outros recheios (BRASIL, 2000). A carne moída do hambúrguer pode, portanto, ser adicionada de proteína de soja hidratada, $1 \%$ de sal, $0,2 \%$ de glutamato monossódico e especiarias (PARDI et al., 1994). Porém, de acordo com os requisitos de composição (BRASIL, 2000) só é permitida a "adição máxima de $4,0 \%$ de proteína não-cárnica na forma agregada".

Os requisitos das características sensoriais do hambúrguer envolvem textura, cor, sabor e odor próprios (BRASIL, 2000). Também devem atender as seguintes características físico-químicas: gordura (máxima) 23,0\%; proteína (mínima) 15,0\%; carboidratos totais 3,0\%; teor de cálcio (máximo base seca) $0,1 \%$ em hambúrguer cru e $0,45 \%$ em hambúrguer cozido (BRASIL, 2000).

O acondicionamento prevê embalagem com materiais adequados para as condições de armazenamento e que confiram proteção apropriada ao hambúrguer (BRASIL, 2000). Na exposição à venda, os produtos devem ser mantidos sob congelamento.

\section{FATORES QUE INFLUENCIAM A MICROBIOTA DO HAMBÚRGUER E PADRÕES MICROBIOLÓGICOS ESTABELECIDOS PELA AGÊNCIA NACIONAL DE VIGILÂNCIA SANITÁRIA (ANVISA)}

Os alimentos podem oferecer riscos potenciais de natureza biológica, química e/ou física para a saúde humana. São conhecidas mais de 250 doenças transmitidas via alimentos (DTA), sendo as infecções bacterianas as causas mais comuns (TEIXEIRA NETO, 1999).

A qualidade higiênico-sanitária de alimentos de origem animal sempre foi alvo de preocupação e destaque pela possibilidade de veiculação de microrganismos patogênicos (NASCIMENTO e NASCIMENTO, 2000).

Aspectos intrísecos e extrínsecos devem ser considerados no surgimento de problemas microbiológicos em produtos cárneos (CLARK e TAKACS, 1980; ICMS, 1983; DELAZARI, 1984; SOUZA et al., 2000; DOWNES e ITO, 2001; INPPAZ, 2001). Os intrínsecos envolvem atividade de água (Aa) elevada, $\mathrm{pH}$ próximo da neutralidade, potencial de óxido-redução (Eh) positivo (para microrganismos aeróbios) ou negativo (para microrganismos anaeróbios) e composição química rica em nutrientes 
favoráveis ao crescimento microbiano. Os extrínsecos incluem umidade relativa, movimentação do ar, atmosfera, sanitização do ambiente, maquinário e utensílios, tempo de armazenamento, temperatura e manipulação do produto. Esses fatores influenciam decisivamente a microbiota capaz de contaminar e proliferar nos hambúrgueres, tendo importância sob o ponto de vista da Saúde Pública.

As alterações bioquímicas "post-mortem" que acontecem no músculo, modificando o $\mathrm{pH}$ afetam alguns atributos muito importantes na qualidade da carne, como maciez, sabor, capacidade de retenção de água e conservabilidade (HOFMANN, 1988).

É necessário aperfeiçoar constantemente as ações de controle sanitário na área de alimentos. A legislação brasileira regulamenta e compatibiliza os padrões microbiológicos para a comercialização de alimentos especificados, visando a proteção da saúde da população. Os limites de tolerância para as bactérias patogênicas de hambúrgueres, abrangidas na legislação, são apresentados na Tabela 2 (BRASIL, 2001).

\section{TABELA 2 - TOLERÂNCIA MÁXIMA E PADRÕES MICROBIOLÓGICOS, ESTABELECIDOS PELA ANVISA, PARA HAMBÚRGUERES}

\begin{tabular}{|c|c|c|c|c|c|}
\hline \multirow{2}{*}{ Microrganismo } & \multirow{2}{*}{$\begin{array}{c}\text { Toleráncia } \\
\text { para a } \\
\text { amostra } \\
\text { indicativa } \\
\end{array}$} & \multicolumn{4}{|c|}{$\begin{array}{c}\text { Toleråncia para amostra } \\
\text { representativa }\end{array}$} \\
\hline & & n & $c$ & $\mathrm{~m}$ & M \\
\hline Staphylococous coegulase positivalg & $5 \times 10^{3}$ & 5 & 2 & $10^{3}$ & $5 \times 10^{3}$ \\
\hline Samonello sp. $/ 25 \mathrm{~g}$ & Aus. & 5 & 0 & Aus & $\cdot$ \\
\hline Colitormas $845^{\circ} \mathrm{C}$ & $5 \times 10^{3}$ & 5 & 3 & $5 \times 10^{2}$ & $5 \times 10^{3}$ \\
\hline Costridum sults redutor a $46^{\circ} \mathrm{Clg}$ & $3 \times 10^{3}$ & 5 & 2 & $5 \times 10^{2}$ & $3 \times 10^{3}$ \\
\hline
\end{tabular}

$\mathbf{n}=$ número de unidades a serem coletadas aleatoriamente do mesmo lote e analisadas individualmente.

c = número máximo aceitável de unidades de amostras com contagens entre os limites "m" e "M".

m = limite que, em plano de três classes, separa o lote aceitável do produto ou lote com qualidade intermediária aceitável.

$\mathbf{M}=$ limite que, em plano de duas classes, separa o produto aceitável do inaceitável. Em plano de três classes, $\mathbf{M}$ separa o lote com qualidade intermediária aceitável do lote inaceitável. Valores acima de $\mathbf{M}$ são inaceitáveis.

Aus. = ausência em $25 \mathrm{~g}$.

Fonte: ANVISA (BRASIL, 2001). 
As análises microbiológicas rotineiras são indicativas de aspectos relacionados à higiene industrial, manipulação e estocagem dos hambúrgueres, sendo muito importantes na manutenção das condições de consumo pelo maior tempo possível. A condição microbiológica do alimento determinará a sua salubridade e qualidade de conservação (DELAZARI, 1984).

A legislação brasileira não estabelece limites de tolerância para contagem total de microrganismos aeróbios, contagem de coliformes a $35^{\circ} \mathrm{C}$ e contagem total de fungos filamentosos e leveduras para hambúrgueres (BRASIL, 2001).

\section{CONTAGEM TOTAL DE AERÓBIOS MESÓFILOS EM PLACA: INDICADOR DE QUALIDADE HIGIÊNICO-SANITÁRIA}

O método da Contagem Total de Aeróbios Mesófilos em Placa, também conhecido como Contagem Total em Placa (CTP), Contagem Padrão em Placa ou Contagem de Aeróbios em Placa fornece estimativa do número total de bactérias aeróbias no alimento, em vez de determinado microrganismo (NASCIMENTO e NASCIMENTO, 2000). Tem sido utilizado como um dos indicadores microbiológicos para avaliar a qualidade de alimentos com base em sua condição sanitária. A contagem da população microbiana capaz de crescer como colônias visíveis sob as condições testadas laboratorialmente é estimada em Unidades Formadoras de Colônias por grama de alimento (UFC/g) (ELLIOTT, 1980). Dependendo da situação, a CTP pode constituir ferramenta valiosa para avaliar a qualidade dos alimentos. Número elevado de bactérias na contagem total em placa pode ser indicativo de sanitização deficiente, ou problemas no processo e/ou ingredientes (MORTON, 2001).

As bactérias aeróbias mesófilas não são usadas na avaliação dos riscos de toxinfecções alimentares, porém constituem um dos mais seguros grupos de indicadores de qualidade microbiológica (CARVALHO, 1995).

A contagem microbiana no produto final reflete a qualidade da matériaprima, a eficácia de métodos de limpeza e desinfecção na indústria de processamento, tipo de manipulação, tempo e temperatura usadas durante a produção, transporte e/ou estocagem do alimento (SANT'ANA, CONCEIÇÃO e AZEVEDO, 2002). Pode ser utilizada para a detecção dos pontos de contaminação durante o processamento, fornecendo noção sobre determinadas alterações incipientes do alimento, sua aceitabilidade 
e estimar o tempo de prateleira produto (ELLIOT, 1980; MORTON, 2001). É possível visualizar, que a melhor maneira de se avaliar a segurança do alimento envolve a contagem do número de bactérias presentes na amostra. A CTP foi criada para essa finalidade, sendo o método mais usado, mundialmente, para determinar a qualidade sanitária de produtos alimentares (UCDAVIS, 1987). A CTP pode ser usada para verificar as condições microbiológicas das carcaças na indústria receptora para identificação (rastreamento) de fornecedores que estejam enviando carcaças com nível excessivamente alto de contaminação. Também pode ser usada para avaliar as condições sanitárias de equipamentos e utensílios durante o processamento e monitorar as condições de higiene (MORTON, 2001).

ROSSI JÚNIOR (1984) examinou amostras de hambúrgueres de duas fontes distintas, provenientes de Jaboticabal-SP, quanto à CTP. Encontrou resultados superiores a $3 \times 10^{6} \mathrm{UFC/g}$ na contagem de mesófilos aeróbios em 11 amostras adquiridas em lanchonetes (representando 33,6 \% dos resultados), enquanto que no produto proveniente de indústrias esses valores não excederam $10^{5} \mathrm{UFC} / \mathrm{g}$.

Variação na contagem de aeróbios mesófilos em placa foi pesquisada em diferentes tipos de carnes processadas. Para hambúrguer foi observada baixíssima variação nos resultados da CTP, revelando processamento uniforme da carne utilizada na sua produção (BERG e HILDEBRANDT, 1996).

TORNER, CASTILHO e HERNANDORENA (1995) observaram, em estudo realizado em Xativa (Espanha), que acima de 50,0\% (14/26) dos hambúrgueres examinados apresentaram CTP maior que o máximo permitido pela legislação para a enumeração de mesófilos aeróbios. GILL et al. (1996), pesquisando a qualidade higiênica de carne destinada a fabricação de hambúrgueres, encontraram pela CTP valores entre 3,5 4,9 $\log _{10}$ de UFC/g nas amostras analisadas.

NASCIMENTO et al. (2003) levantaram as condições microbiológicas de hambúrgueres de carne bovina de duas marcas comerciais ("A" e "B"), mediante CTP. Encontraram 6,6\% (1/15) das amostras da marca "A" e $60,0 \%(9 / 15)$ das amostras da marca "B" com valores acima de $10^{5} \mathrm{UFC} / \mathrm{g}$.

A legislação brasileira vigente não estabelece limite de tolerância microbiológico para o número total de bactérias aeróbias mesófilas por 
grama de hambúrguer (BRASIL, 2001). Porém, tem sido observado que contagem (CTP) acima de $10^{5} \mathrm{UFC/g}$ em carne moída fresca compromete o produto em relação à sua qualidade higiênico-sanitária (MORTON, 2001). A CTP de produtos crus pode apresentar flutuações muito grandes nas contagens. Neste caso, a CTP não forneceria dados significativos em relação à aceitação do produto, mas poderia contribuir para a pesquisa dos fatores responsáveis pela flutuação das contagens (MORTON, 2001). A limpeza aparente pode induzir a erros e fornecer falsa idéia de segurança, por isso a inspeção das condições de higiene quanto à contaminação microbiológica deve ser realizada após a higienização (SIQUEIRA JÚNIOR et al., 2004).

\title{
6 CONCLUSÃO
}

Em comparação com os países europeus, o Brasil foi o maior consumidor de carne bovina em 2003. A modernidade mudou os hábitos alimentares e o consumo nacional de hambúrguer congelado tem sido superior, em volume, ao de outros produtos cárneos congelados.

De acordo com os estudos microbiológicos relatados, a CTP constitui um dos melhores indicadores microbiológicos para avaliação da qualidade higiênico-sanitária de alimentos. A CTP deveria ser usada para hambúrgueres crus, visando indentificar deficiências na sanitização, problemas no processo ou em ingredientes na indústria e diminuir a carga microbiana do produto cru.

\begin{abstract}
HAMBURGER: COMMERCIAL EVOLUTION AND MICROBIOLOGICAL STANDARDS

In this literature review work, it was described the hamburger evolutionary aspects (since its origin), standing out the "per capita" consumption of meat, its continuous increase in commercial trade and consumption. The factors that influence the hamburger microbiot and the microbiological standard established for the product by the National Agency of Sanitary Surveillance (ANVISA) were also discussed. Additionally, a brief discussion was made about the use of the Total Plate Count of Mesophilic Bacteria (TPC) as a tool for measuring microbiological quality in meat and hamburger, and its exclusion from Brazilian Legislation for those foods. The inclusion of TPC in the standards adopted for raw hamburgers, seeking to decrease the microbiological load of the product is suggested.
\end{abstract}

KEY-WORDS: HAMBURGER; MEAT - MICROBIOLOGICAL QUALITY; TPC. 


\section{REFERÊNCIAS}

1 ABAMEC. Associação Brasileira dos Analistas do Mercado de Capitais. Resultados do $1^{\circ}$ Trimestre de 2002. Perdigão [S.I.], 2002. Disponível em: <http://www.perdigao.com.br/ingles/empresa/info/ frinfo.htm>. Acesso em: 20 jul. 2002.

2 ABIEC. Associação Brasileira dos Exportadores de Carne Bovina. Volume das Exportações de Carne Bovina [S.I.], 2004. Disponível em: <http://www.abiec.com.br>.Acesso em 22 jun. 2004.

ABIPECS. Associação Brasileira da Indústria Produtora e Exportadora de Carne Suína. Consumo per capita das principais carnes, União Européia - 15. Em Foco - Informativo da Associação Brasileira da Indústria Produtora e Exportadora de Carne Suína ABIPECS. [S.I.], n. 37, mai. 2004. Disponível em: <http:www.abipecs.com.br/foco8_04_abipecs37.pdf>. Acesso em: 19/02/2005.

AEB. Associação de Comércio Exterior do Brasil. Exportação Brasileira. [S.I.], 2004. Disponível em: <http:// www.aeb.org.br/ home.htm>. Acesso em 22 jun. 2004.

ALVES, J.A.M. O sanduíche globalizado. O Estado de S. Paulo. São Paulo, 1999. Disponível em: http://www.estado.estadao.com.br/ jornal/suplem/fem/99/02/13/fe26.html. Acesso em: 01 ago. 2002.

BERG, C.; HILDEBRANDT, G. Variance of mesophilic aerobic plate counts in coarsely chopped particulate meat products: Mettwurst, fresh ground beef and hamburgers. Fleischwirtschaft, v. 76, n. 6, p. $644-648,1996$.

BRASIL. Ministério da Agricultura e do Abastecimento. Regulamento técnico de identidade e qualidade de hambúrguer. Instrução Normativa ํㅡ 20, de 31/07/2000. Diário Oficial [da] República Federativa do Brasil, Brasília, 31/07/2000, p. 7-9.

BRASIL. Ministério da Saúde. Agência Nacional de Vigilância Sanitária (ANVISA). Resolução RDC № 12, de 02/01/2001. Regulamento técnico sobre padrões microbiológicos para alimentos. Diário Oficial [da] República Federativa do Brasil, Brasília, 02/01/2001, p. 1-54.

CARVALHO, I.M. Avaliação bacteriológica de hamburger de frango comercializado no município do Rio de Janeiro. Niterói, 1995. 156 p. Tese (Mestrado em Tecnologia de Alimentos), Centro de Ciências Médicas, Universidade Federal Fluminense. 
CAVALCANTI, M. Hambúrguer conquista o apetite dos consumidores. O Globo, Rio de Janeiro, 28 de maio de 1993. Caderno de Economia C1/C2, p. 15.

11 CLARK, D.S.; TAKACS, J. Gases as preservatives. In: ICMSF. International Comission on Microbiological Specification for Foods. Factors affecting life and death of microrganisms. New York: Academic Press, 1980. v. 1, p. 311.

12 DELAZARI, I. Controle microbiológico de qualidade na indústria de carne. In: CICLO DE PALESTRAS SOBRE A INDÚSTRIA DA CARNE, 1984, São Paulo. Apostila... São Paulo: Sociedade Paulista de Medicina Veterinária, 1984. p. 62 - 65.

13 DOWNES, F.P.; ITO, K. (Ed.). Compendium of Methods for the Microbiological Examination of Foods. $4^{\text {th }}$ ed. Washington, DC. APHA, 2001. $676 \mathrm{p}$.

14 ELLIOTT, R.P. The microbiology of sanitation. In: KATSUYAMA, A.M.; STRACHAN, J.P. (Ed.). Principles of food processing sanitation. Washington D.C.: The Food Processing Institute, 1980. p. 39 - 60.

15 GARNIER, J.P.; KLONT, R.; PLASTOW, G. The potential of current animal research on the meat industry and consumer attitudes towards meat. Meat Science, v. 63, n. 1, p. 79-88, 2003.

16 GERDAU. Produtos agropecuários: o hambúrguer é o novo embaixador da carne bovina junto ao mercado consumidor. [S.I.], 2001. Disponível em: <http:// www.amigosdocampo.com.br/ fasciculos/num_01/pag_2.htm>. Acesso em: 29 jun. 2002.

17 GILL, C.O.; McGINNIS, J.C.; RAHN, K.; HOUDE, A. The hygienic condition of manufacturing beef destined for the manufature of hamburger patties. Food Microbiology, v. 13, n. 5, p. 391 - 396, 1996.

18 HOFMANN, K. El pH: una característica de calidade de la carne. Fleischwirstch, Espanol, v. 1, p. 13 - 18, 1988.

19 HOOGENKAMP, H.W. Meat Patties: formulating for today's consumer. Meat International, v. 6, n. 6, p. 30-32, 1996.

20 IBGE. Instituto Brasileiro de Geografia e Estatística. Pesquisa Trimestral de Abate de Animais - Resultados Mensais, IBGE [S.I.], 2004. Disponível e: <http://www.sidra.ibge.gov.br>. Acesso em 22 jun. 2004. 
21 ICMS. International Comission on Microbiological Specification for Foods. Microrganismos de los Alimentos. 1-Técnicas de Análises Microbiológicas. $2^{\text {nd }}$ ed. Zaragoza: Acríbia, 1983. 431 p.

22 INFORMATIVO SECEX. Mercado Selecionado. Chile: um destaque na América Latina. Brasília, jan. 2003. Disponível em: <http// www.desenvolvimento.gov.br/ arquivo/secex/ informativos/ info33.pdf>. Acesso em: 22 jan. 2004.

23 INPPAZ. Instituto Panamericano de Proteccion de Alimentos y Zoonosis. Argentina, 2001. Disponível em: <http://www.inppaz.org.ar/ >. Acesso em: 12 jul. 2002.

24 ION INFORMATION NETWORK. Geomarketing aplicado ao hambúrguer [S.I.], mai. 2003. Disponível em: <http://www.ion.com.br/>.Acesso em: 29 jun. 2004.

25 MAGOSSI, E. Brasil deve exportar US $\$ 1,4$ bi em carnes em 2003. 0 Estado de S. Paulo., São Paulo, 25 nov. 2000. Disponível em: <http:// www.estadao.com.br/agestado/nacional/2000/nov/25/ 6.htm.>. Acesso em: 06 jul. 2002.

26 METZGER, F.; TEIXEIRA, M.R. Trabalhos finais da OfJor Comida global, estômago local. [S.I.],1997. Disponível em: <http://www.observatoriodaimprensa.com.br/ofjor/estomago.html>. Acesso em: 14 jun. 2002.

27 MOREIRA, F.B.; SOUZA, N.E.; MATSUSHITA, M.; PRADO, I.N.; NASCIMENTO, W.G. Evaluation of carcass characteristics and meat chemical composition of Bos indicus and Bos indicus $x$ Bos taurus crossbred steers finished in pasture systems. Brazilian Archives of Biology and Technology, v. 4, p. 609-616, 2003.

28 MORTON, R.D. Aerobic plate count. In: DOWNES, F.P.; ITO, K. (Eds). Compendium of Methods for the Microbiological Examination of Foods. Washington: American Public Health Association (APHA), 2001. cap. 7, p. 63 - 67.

29 NASCIMENTO, M.G.F.; NASCIMENTO, E.R. Importância da avaliação microbiológica na qualidade e segurança dos alimentos. Seropédica: Embrapa Agrobiologia, dez. 2000. 11 p. (EmbrapaCNPAB. Documentos, 120).

30 NASCIMENTO, M.G.F.; OLIVEIRA, C.Z.F.;NASCIMENTO, E.R.; SIQUEIRA, R.S.; FARIAS, A. Bioindicators of contamination in commercially available bovine hamburgers of two trademarks. In: CONGRESSO BRASILEIRO DE MICROBIOLOGIA, 22., 2003. 
CDR....Florianópolis: Sociedade Brasileira de Microbiologia, 2003.

31 PARDI, M.C.; SANTOS, I.F.; SOUZA, E.R.; PARDI, H.S. Ciência, Higiene e Tecnologia da Carne. Rio de Janeiro: UFG/EDUFF, 1994, 1110 p. v. 2.

32 PARIZOTTO, T. Bovinocultura à base de sementes. Jornal da UEM, Maringá, Março, p. 3, 2004.

33 PERDIGÃO. Handouts $3^{\circ}$ Trimestre, 2004. [S.I.], 2004. Disponível em: <http://www.perdigao.com.br/ri/port/download/apresentacoes/ 3Tri04>. Acesso em: 20 fev. 2005.

34 PINEDA, N.P.; ALMEIDA, A.V.L. Mercado de carne bovina e o Serviço de Informação da Carne. Revista Nacional da Carne, São Paulo, n. 317, mar. 2003. Disponível em: <http://www.dipemar.com.br/carne/ 317/materia.produtos_carne.htm>. Acesso em: 02 jul. 2004.

35 PRADO, I.N.; MATSUSHITA, M.; VISENTAINER, J.V.; SOUZA, N.E. Carne bovina brasileira: realidade e perspectivas. Revista Nacional da Carne, São Paulo, n. 326, abr 2004, Disponível em:<http:// www.dipemar.com.br/carne/326/materia_arttec_carne.htm>. Acesso em: 01 jul. 2004.

36 RODRIGUES JÚNIOR, J.M. Mercado externo carne bovina - 3 Mercados: consumo per capita mundial de carne bovina. Seminário on line, Curitiba, ago. 2003. Disponível em: <http://www.faep.com.br/ comissoes/corteo_mercado_externo.ppt> Acesso em: 01 mar. 2005.

37 ROMANS JÚNIOR; COSTELLO, W.J.; JONES, K.W. et al. The Meat we eat. $12^{\text {th }}$ ed. lilinois: The Inter-State Printers and Publishers, 1985. $850 \mathrm{p}$.

38 ROSSI JÚNIOR, O.D.R. Contribuição aos estudos de padrões sanitários em carnes de hambúrguer adquiridas no comércio varejista da Jaboticabal-SP. 1984. 74 p. Tese (Mestrado em Medicina Veterinária), Universidade Federal Fluminense, Niterói, 1984.

39 SANT'ANA, A.S.; CONCEIÇÃO, C.; AZEREDO, D.R.P. Comparação entre os métodos rápidos Simplate TPC-Cl e Petrifilm AC e os métodos convencionais de contagem em placas, para a enumeração de aeróbios mesófilos em sorvetes. Rev. Higiene Alimentar, São Paulo, v. 16, n. 95, p. 82 - 87, abr. 2002.

40 SINK, J.D. Industrial modeling output estimates of ground beef industry. Food Technology, Chicago, v. 34, n. 6, p. 58-62,1980. 
41 SIQUEIRA JÚNIOR, W.M.; CARELI, R.T.; ANDRADE, N.J.; MENDONÇA, C.S. Qualidade microbiológica de equipamentos, utensílios e manipuladores de uma indústria de processamento de carnes. Revista Nacional da Carne, São Paulo, n. 326, 2004. Disponível em: <http://www.dipemar.com.br/carne/317/ materia.produtos_carne.htm>. Acesso em: 01 jul. 2004.

42 SOARES, P. Exportações de carne aumentaram 54\%. Gazeta Mercantil, São Paulo, mai. 2004. Disponível em: <http:// www.gazetamercantil.com.br>. Acesso em: 16 jun. 2004.

43 SOUSA, C.L.; PEIXOTO, M.R.S.; NASSAR, R.N.M.; CASTRO, E. Microbiologia da carne bovina moída no município de Macapá-AP. In: CONGRESSO BRASILEIRO DE CIÊNCIA E TECNOLOGIA DE ALIMENTOS, 1., 2000, Fortaleza. Anais... Fortaleza: Sociedade Brasileira de Ciência e Tecnologia de Alimentos, 2000. p. 428.

44 TEIXEIRA NETO, R.O. Um alimento inócuo é fruto de respeito. Revista Banas Qualidade, São Paulo, v. 8, n. 85, p. 96 - 102, jun. 1999.

45 TORNER, M.J.; CASTILHO, M.; PLA, S.; HERNANDORENA, M.J. A study of the sanitary quality of fresh meat products manufactured in meat processing plants in the health area of Xativa. Alimentaria, Xavita, 262, p. 27 - 31, 1995.

46 UCDAVIS. University of California. Food Science and Technology 104L: Laboratory Syllabus. Davis, 1987. 104 p. 